\title{
Topic Study Group No. 43: Uses of Technology in Upper Secondary \\ Education (Age 14-19)
}

\author{
Stephen Hegedus, Colette Laborde, Luis Moreno Armella, \\ Hans-Stefan Siller and Michal Tabach
}

\section{The Programme}

TSG 43 addressed the use of technology in upper secondary mathematics education from four points of view:

- theoretical analysis of epistemological and cognitive aspects of activity in new technology mediated learning environments;

- the changes brought by technology in the interactions between environment, students and teachers;

- the interrelations between mathematical activities and technology;

- skills and competencies that must be developed in teacher education.

The group received 42 submissions for a presentation and 5 posters coming from 23 different countries. From these submissions, 12 were selected for a long presentation during the sessions of the Topic Study Group. The other submissions gave rise to short oral communications in slots external to the sessions of the Topic Group. In order to stimulate and structure the discussion, four additional presentations were planned by the Topic Group for introducing the four main themes of the group: they were done by L. Moreno Armella and C. Brady, S. Hegedus and

Co-chairs: Stephen Hegedus, Colette Laborde.

Team members: Luis Moreno Armella, Hans-Stefan Siller, Michal Tabach.

\author{
S. Hegedus \\ Southern Connecticut State University, New Haven, CT, USA \\ e-mail: hegeduss1@ southernct.edu \\ C. Laborde $(\square)$ \\ Cabrilog, Fontaine, France \\ e-mail: colette.laborde@cabri.com \\ (C) The Author(s) 2017


S. Dalton, by H.-S. Siller, by M. Tabach and J. Trgalova. These presentations gave rise to an ICME 13-Topical Survey (Hegedus et al., 2016).

The programme of the TSG was organized with the intention of meeting three aims: bringing information, supporting discussion and formulating critical questions for the future.

The first session was devoted to these four presentations providing a state of art presentation of the four main issues mentioned above and formulating critical questions related to those issues. The long presentations took place in the second and third sessions in parallel. The fourth session was a collective session divided into three parts:

- showcase examples of uses of technology by participants;

- discussion of issues raised during the previous sessions in small groups;

- reports summarizing the group discussion and conclusion.

A large diversity of themes was addressed by the presentations and during the discussion slots. The following section summarizes the main issues and questions of the group sessions.

\section{Main Issues and Questions}

\section{Technologies at use}

Although the group called for presentations about new emerging technologies, the presentations mainly dealt with "classical" technology like Dynamic Geometry Environments or CAS, but with a stronger focus on Dynamic Geometry Environments in the long presentations as well as in short oral communications.

Three presentations only reported about the use of emerging technologies: multimodality involving various sensory modalities (like sight, touch, sound), 3D augmented realities, 3D pen, Wii graph a software application modeling the movement of two controllers of the game console Nintendo Wii. It is interesting to note that the two studies about 3D pen and Wii console shared a common theoretical framework in which diagrams and gestures are strongly linked and in which the meaning of mathematical objects is to be found in the interactions between diagrams and gestures. This framework can also be linked to the notion of co-action (Moreno-Armella \& Hegedus, 2009): the learner is co-acting with the representational systems of mathematics offered by dynamic technologies.

Topics and questions

The most mentioned technological environments were Dynamic Geometry Environments or Dynamic Mathematics Environments. In the presented studies, they were used 
- for teaching specific notions;

- for modeling; in particular, a study shows that technology is used at different stages in the modeling cycle;

- for fostering exploration.

Some participants mentioned that it would be nice to see more applications/investigations in other areas than geometry, algebra, in particular. There is an innate appeal to the visual nature of DGE, so that CAS teaching questions are challenging. Of course, it must be kept in mind that algebra is not only accessible through CAS.

However, some presentations addressed issues related to the use of CAS. A focus was made in particular on justification and proof. There may be changes in the type of justification brought in textbooks when using a CAS. The example of Denmark was given. In this country, more than one textbook make use of CAS assisted proof, i.e. a proof of a theorem or a statement when steps are outsourced to a CAS. The number of steps may vary from one or few steps to the whole proof, the CAS playing the role of an authority. A connected issue was addressed about the norms for evaluating the work of students solving problems by means of a CAS. In absence of verbalization, it may be difficult to reconstruct the work of the students.

This discussion about CAS and justification raised the questions of the emergence of new norms when using technology and not only for CAS. A study devoted to the use of graphing calculators showed that students using calculators were asking less critical and less why questions than those not using calculators. There is presently an absence of policy that may make the situation difficult for teachers.

Problems as well as contribution brought by the use of technologies for teachers in their teaching and teacher education were addressed by several presentations and gave rise to discussion. As shown in some presentations, new opportunities of interaction between the teacher and the students may emerge due to the presence of technology providing feedback to students' actions. The nature of these opportunities and the role of the teacher within these new forms of interactions constitute a wide field to investigate. For example, what are the new ways of interaction among multiple students or between students and their teacher that can occur as a result of these digital technology tasks?

It seems that there is a need of investigating the impact of research on teacher development: in what ways can research provide or has research provided teachers with knowledge, recommendations, and professional development around an optimal use of student work with digital technologies to take advantage of what the digital tools have to offer?

Teachers' choices, views and norms seem to play a crucial role for a successful integration. A study reported how new socio and socio-mathematical norms emerge in technology enhanced lessons done by preservice teachers. In particular, more justifications are requested from students by the teacher and discussion among students about the "reasons" was encouraged. This led to a more general question: Are there any interesting ways of taking advantage of technology for working with proofs in math classrooms? 
Teachers' beliefs regarding discovering learning and time constraints are most influential when determining frequency of technology use. Teachers supporting discovery learning are more inclined to resort to the use of technology whereas paying much attention to time constraints may prevent them from integrating often technology often into their teaching.

\section{Conclusion}

From the whole set of presentations and discussions emerged the complexity of the questions of the use of technology in the teaching and learning of mathematics. The studies shed light on many interactions between the mathematical structures and their representations in technology environments, between the learners, the environments and the task they are faced with, between the teacher interventions and the students' work on technology, between teachers' beliefs and the frequency and type of use of technology.

Research developed several theoretical tools for analyzing these interactions but the question of the dissemination of these studies and their possible use by teachers is still remaining.

How to disseminate research-based tasks with technology (designed by researchers or teacher educators) in a way to help teachers use them "properly"? In the case of collaborative design of tasks (by groups of teachers and researchers/teacher educators), how should researchers/teacher educators act in a way not to impose their research view but leading towards tasks with required educational quality?

"How to motivate teachers to adopt technology?" was among the final questions of the group ...

\section{References}

Hegedus, S., Laborde, C., Brady, C., Dalton, S., Siller, H.-S., Tabach, M., et al. (2016). Uses of technology in upper secondary mathematics education. ICME-13 topical surveys. Cham: Springer Open.

Moreno-Armella, L., \& Hegedus, S. J. (2009). Coaction with digital technologies. ZDM Mathematics Education 41(4), 505-519.

Open Access Except where otherwise noted, this chapter is licensed under a Creative Commons Attribution 4.0 International License. To view a copy of this license, visit http://creativecommons. org/licenses/by/4.0/.

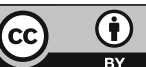

